\title{
PREVALENCE OF BREAST ABNORMALITIES FOUND IN ULTRASSOUND
}

Laís L. Neves', Fernanda G. Filardi', Dânisa S. Carrijo', Julia B. Gomes', Milena V. M. Moreira', Felipe Augusto A. Carvalho', Raphael Costa Lima'1, Waldemar Naves Amaral²

${ }^{1}$ Faculdade de Medicina, Centro Universitário de Anapólis (UniEVANGÉLICA) - Anápolis (GO), Brazil.

${ }^{2}$ Faculdade de Medicina, Universidade Federal de Goiás - Goiânia (GO), Brazil.

Introduction: Breast disorders are very frequent in the female population, and can be divided into benign and malignant ones. For its evaluation, ultrasonography (USG) provides important information on breast findings, providing additional data to the other diagnostic methods. Within this, the Breast Imaging Reporting and Data System (BI-RADS) classification universalizes the diagnosis and assists in the standardization of an examination that is a dependent operator. Objectives: Quantify the prevalence of normal findings in breast USG, establish the most frequent pathological findings in breast USG and establish the frequency of BI-RADS findings. Methodology: This is a cross-sectional retrospective descriptive study, carried out with 209 breast ultrasonography reports from the Center for Fetal Medicine and Human Reproduction of Goiânia - Fértile Diagnósticos, carried out in 2016 and 2017. Results: Considering the whole sample, 209 mammary USG reports, of which 143 had unchanged results $(68.42 \%$ ), with $80 \%$ of reports classified as BI-RADS 1 (absence of abnormal findings). The second BI-RADS most found was classified as 2, in which was found 10,5\% of benign abnormalities. Already $31.5 \%$ of the reports presented sonographic alterations, with the main abnormality observed being the benign functional alterations, present in $56 \%$ of them. Then, the cystic nodes occupied the position of the second most frequent abnormality (36.6\%). It also was analyzed 16 reports of solid nodules (24.4\%). Conclusion: In this way, the prevalence of normal USG was $68 \%$, whereas among the altered reports, benign functional alterations were the most frequent followed by solid nodules. Regarding BI-RADS, types 1 and 2 were the most found, according to Brazilian literature. 